\title{
Glutathione S-transferases in the organ of Corti of the rat: Enzymatic activity, subunit composition and immunohistochemical localization
}

\author{
Aida El Barbary, Richard A. Altschuler and Jochen Schacht * \\ Kresge Hearing Research Institute, Department of Otolaryngology, University of Michigan, 1301 East Ann Street, Ann Arbor, MI 48109-0506, USA
}

(Received 15 January 1993; Revision received 9 July 1993; Accepted 15 July 1993)

\begin{abstract}
Glutathione S-transferases (GSTs), a family of ubiquitous cytosolic isozymes, catalyze the detoxification of electrophilic substrates with reduced glutathione and participate in intracellular binding and transport of lipophilic substances. This study measured GST activity biochemically in the inner ear of the rat; determined the isozyme profile by Western blotting; and identified, immunohistochemically, the distribution of the $\mu$ and $\pi$ class GSTs in the organ of Corti. GST enzymatic activity in inner ear tissues ranged from 117 to 348 nmoles glutathione converted $/ \mathrm{min} / \mathrm{mg}$ protein, values somewhat higher than those found in brain (130) and much lower than in liver (1011). Of the GST isoforms, the $\pi$ class (identified by antibodies against the $Y_{p}$ subunit) was most prominent, the $\mu$ class ( $Y_{b 1}$ subunit) clearly evident while the $\alpha$ class $\left(\mathrm{Y}_{\mathrm{a}}\right.$ subunit) was barely detectable on Western blots. Immunocytochemical analysis showed differential distribution of the $\mathrm{Y}_{\mathrm{h}, \mathrm{l}}$ and $\mathrm{Y}_{\mathrm{p}}$ subunits. The $\mathbf{Y}_{\mathbf{b} 1}$ subunit was present in the sensory cells, while supporting cells were not spccifically stained. At the subcellular level, the isozyme was localized in the apical zones of inner (IHCs) and outer hair cells (OHCs) close to the cuticular plate. The extent of staining, however, varied between OHCs and IHCs. In the OHCs, staining appeared in discrete spots in the apical areas only, whereas in IHCs staining extended further towards the center of the cells. The $Y_{p}$ subunit was mainly localized to Deiters cell processes and pillar cells. Both $Y_{b}$ and $Y_{n}$ colocalized with tubulin-specific antibody.

The functional significance of GST in the cochlear receptor cells is speculative. However, a role anologous to that in other tissues (detoxification, prostaglandin synthesis) can be assumed. In addition, an association of GST with the microtubule system is possible based on immunohistochemical colocalization with tubulin.
\end{abstract}

Glutathione S-transferases; Hair cells; Basal body; Microtubule; Detoxification; Western blot; Deiters cells

\section{Introduction}

Glutathione S-transferases (GSTs; EC 2.5.1.18) are a family of cytosolic enzymes present in many tissues (Jakoby, 1978; Boyer, 1989). Multiple forms of the protein originate from homo- and heterodimeric combinations of different subunits (Mannervik et al., 1985; Habig et al., 1974) resulting in GST isozymes of varying catalytic properties and antigenic specificity. Each subunit contains one binding site for glutathione and another for a hydrophobic domain on the substrate (Mannervik and Danielson, 1988). Mammalian GSTs fall into three major classes based on their subunit composition. GSTs containing $Y_{a}$ and $Y_{c}$ subunits are categorized as $\alpha$, those with $Y_{\mathrm{b}}$ subunits as $\mu$, and those with $Y_{p}$ subunits as $\pi$ (Mannervik et al., 1985). Additional diversity arises from further subclasses within each group of subunits.

GST activity varies considerably between tissues and species. Tissue-specific expression and sex differences in subunit composition as well as age-related changes

\footnotetext{
* Corresponding author. Fax: (313) 764-0014.
}

in emzymatic properlies contribute to distinct activity and specificity patterns (Mannervik, 1985; Hayes and Mantle, 1986; Rogiers et al., 1991; Carrillo et al., 1991). In the central nervous system of the rat, GSTs of the $\mu$ class have been localized immunohistochemically to astrocytes, subventricular zone cells and ependymal cells (Abramovitz et al., 1988; Cammer et al., 1989); $\pi$ class GST to oligodendrocytes and in association with myelin (Cammer et al., 1989; Tansey and Cammer, 1991). Neurons had been considered devoid of GST immunoreactivity (Senjo et al., 1986; Abramovitz et al., 1988; Cammer et al., 1989; Tansey and Cammer, 1991) but recently, GSTs have been localized to their cytoplasm, nuclei ( $\mathrm{Y}_{\mathrm{a}}$ subunit) and nuclcoli $\left(\mathrm{Y}_{\mathrm{c}}\right.$ subunit (Johnson et al., 1993).

GSTs play a major role in cellular glutathione homeostasis by catalyzing the conjugation of a wide range of electrophilic substrates with reduced glutathione. These reactions include the detoxification of xenobiotics and the binding of lipophilic compounds such as glucocorticoids, heme and bilirubin (Jakoby, 1978; Maruyama and Listowsky, 1984; Listowsky et al., 1988; Manmervik and Danielson, 1988). Depletion of glutathione is thought to be one of the mechanisms by 
which drugs may evoke toxicologic responses (Reed and Fariss, 1984; Meister, 1991). Knowledge of cellular and subcellular distribution of glutathione and its associated enzymes in the inner ear should give insight into the selective susceptibility of cochlear structures to insults. For example, glutathione may be involved in the protection of the inner ear from ototoxic damage by gentamicin (Garetz and Schacht, 1992; Garetz et al., 1993). The current investigation was designed to 1) quantify cochlear GST activity and compare it to that in liver and brain; 2) identify the presence of the $Y_{a}$, $\mathrm{Y}_{\mathrm{b} 1}$ and $\mathrm{Y}_{\mathrm{p}}$ subunits of the $\alpha, \mu$ and $\pi$ class GSTs; and 3) determine the regional as well as the subcellular localization of the GST $Y_{b 1}$ and $Y_{p}$ subunits. The rat was chosen since GSTs have been studied extensively in various tissues of this animal.

\section{Materials and Methods}

\section{Materials}

Experiments were carried out on male Wistar rats (200-250 g body weight; Charles River, Wilmington, MA) kept under pathogen-free conditions. Normal goat serum (NGS), normal rabbit serum (NRS), 3, 3'-diaminobenzidine (DAB) and monoclonal mouse anti b-tubulin (Tub 2.1) antibody were purchased from Sigma Chemical Company (St. Louis, MO). Tetramethyl rhodamine isothiocyanate (TRITC)-conjugated goat anti-mousc IgG and fluorescein isothiocyanate (FITC)-conjugated goat anti-rabbit IgG were obtained from Jackson Immuno Research Laboratories (West Grove, PA); biotinylated goat anti-rabbit IgG and the Vectastain ABC kit (avidin/biotin reagent) from Vector Laboratories (Burlingame, CA). Rabbit anti-rat GST $\left(Y_{b 1}, Y_{p}\right.$ and $\left.Y_{a}\right)$ antisera were purchased from Biotrin (Dublin, Ireland). The $Y_{b 1}$ antibody will crossreact with other subunits within the $\mu$ class $\left(\mathrm{Y}_{\mathrm{b} 2}, \mathrm{Y}_{\mathrm{b} 3}\right.$ and others) but not with subunits of the $\alpha$ or $\pi$ classes. The $Y_{p}$ antibody does not cross-react with the other classes (Hayes and Mantle, 1986; Chang et al., 1990). The dye reagent for protein assay was from BioRad Lab. (Richmond, VA), all other chemicals from Sigma Chemical Co. (St. Louis, MO).

\section{Biochemical assays}

Rats were killed by decapitation. Brain and liver were rinsed with buffer, blotted dry, weighed and homogenized with 3 vol $(\mathrm{w} / \mathrm{v})$ homogenizing buffer $(0.32$ $M$ sucrose, $10 \mathrm{mM}$ Tris- $\mathrm{HCl}, 2 \mathrm{mM}$ EGTA and $1 \mathrm{mM}$ EDTA, $\mathrm{pH}$ 7.5). Cochleas were dissected in homogenizing buffer at $4^{\circ} \mathrm{C}$ into lateral wall tissues (stria vascularis and spiral ligament), neurosensory epithelium (hair cells and supporting cells) and modiolus. Samples from 6-10 cochleas were homogenized in 400 $\mu l$ buffer by sonication on ice (Ultrasonic homogenizer 4710, Cole-Palmer Instrument, Chicago, IL) for $5 \times 2 \mathrm{~s}$, with $20 \mathrm{~s}$ intervals. All tissue homogenates were centrifuged at $12,000 \times g$ for $30 \mathrm{~min}$ at $4^{\circ} \mathrm{C}$. Supernatants were aliquoted and stored at $-20^{\circ} \mathrm{C}$ for later assay of enzyme activities and protein determination.

GST's were assayed after Habig et al. (1974) based on enzyme-dependent thioether formation between reduced glutathione (GSH) and 1-chloro-2,4-dinitro benzene (CDNB) as substrates. The reaction mixture included $0.1 \mathrm{M}$ potassium phosphate buffer $(\mathrm{pH} 6.5)$ with $1 \mathrm{mM}$ EDTA, $1 \mathrm{mM}$ GSH, $1 \mathrm{mM}$ CDNB (from a stock solution of $20 \mathrm{mM}$ in $95 \%$ alcohol) and the enzyme fraction in a final volume of $1 \mathrm{ml}$. Sufficient enzyme was added to give an absorbance change at $340 \mathrm{~nm}$ of approx. $0.05 / \mathrm{min}$, and the reaction was recorded for 5 min. The observed enzymatic rate was corrected by subtracting the spontaneous non-enzymatic rate.

Protein was determined by the Bradford method (1976), with bovine serum albumin (BSA) as standard.

\section{Western blots}

Proteins were separated by sodium dodecyl sulfate polyacrylamide gel electrophoresis (SDS-PAGE) on 5 to $18 \%$ acrylamide gels (Laemmli, 1970). Supernatants from liver, brain, lateral wall tissues and combined modiolus/neuroepithelium were loaded at about 30 $\mu \mathrm{g}$ protein per well. A section of the gel was stained with Coomassie Brilliant blue dye R-250, the rest of the gel was processed for Western blotting.

For Western blot analyses, proteins were transferred to nitrocellulose sheets (pore size: $0.45 \mu \mathrm{m}$; size: $4 \times 51 / 4$ in; Schleicher and Schuell, Keene, NH) at $100 \mathrm{~V}$ for $4 \mathrm{~h}$ (Towbin et al., 1979). The efficiency of the transfer procedure was confirmed in a separate experiment where the nitrocellulose was stained for protein with Naphthol Blue Black (NBB) (0.02 g NBB per $100 \mathrm{ml}$ of aqueous $10 \%$ acetic acid $/ 50 \%$ methanol).

The blots were blocked in a solution consisting of $5 \%$ nonfat dry milk, $0.04 \% \mathrm{NaN}_{3}$ and $0.1 \%$ Tween-20

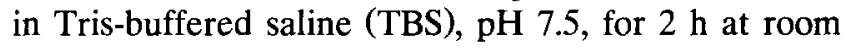
temperature (RT). Blots were then incubated with the primary antibody overnight at $4^{\circ} \mathrm{C}$ at dilutions of $1: 1000$ $\left(\mathrm{Y}_{\mathrm{a}}\right.$ and $\left.\mathrm{Y}_{\mathrm{b} 1}\right)$ and 1:500 $\left(\mathrm{Y}_{\mathrm{p}}\right)$. Antibodies were diluted with TBS containing 3\% nonfat dry milk and $0.1 \%$ Twcen-20. After washing for $30 \mathrm{~min}$ with five changes of TBS, blots were incubated for one $h$ at $R T$ with a secondary biotinylated goat anti-rabbit Ig G (1:1000 dilution; Vector Lab., Burlingame, CA). After several rinses for $30 \mathrm{~min}$ in TBS, blots were incubated for one $\mathrm{h}$ at RT with Avidin/Biotin reagents according to the manufacturer's protocol. Blots were washed again as described and incubated for $10 \mathrm{~min}$ in a peroxidase substrate solution freshly made by mixing $10 \mathrm{ml}$ of $0.3 \%$ 4-chloro-1-naphthol in methanol, $40 \mathrm{ml}$ TBS and $167 \mu \mathrm{l} 30 \% \mathrm{H}_{2} \mathrm{O}_{2}$. Molecular weight standards (Rain- 
bow standard) were from Amersham, Arlington Heights, IL.

\section{Tissue preparation for immunocytochemistry}

Animals were anesthesized by intraperitoneal injection of chloral hydrate $(30 \%, 1 \mathrm{ml} / \mathrm{kg})$ and perfused through the left ventricle with $50 \mathrm{ml}$ phosphate buffered saline (PBS; $0.1 \mathrm{M}$ sodium phosphate and $0.1 \mathrm{M}$ sodium chloride, $\mathrm{pH}$ 7.4) followed by $250 \mathrm{ml}$ of $4 \%$ paraformaldehyde in $0.1 \mathrm{M}$ sodium phosphate, $\mathrm{pH} 7.4$. After removing the temporal bones and opening the bulla, the cochleae were locally perfused through the round window with the same fixative and dissected out for surface preparations. The results reported are mainly from preparations of the apical two turns.

\section{Peroxidase immunohistochemistry}

Surface preparations were preincubated with $40 \%$ NGS and $0.3 \%$ Triton X-100 in PBS for $1 \mathrm{~h}$ at RT followed by an incubation with the primary antibody, rabbit anti-GST $\mathrm{Y}_{\mathrm{bl}}(1: 500$ dilution $)$ for $24 \mathrm{~h}$ at $4^{\circ} \mathrm{C}$. Parallcl controls were run with the primary antibody replaced by NRS or PBS. After three rinses in PBS within $1 \mathrm{~h}$ at RT, samples were incubated for another $\mathrm{h}$ in a 1:500 dilution of biotinylated goat anti-rabbit IgG. After 4 rinses in PBS in $1 \mathrm{~h}$, tissues were further processed with a Vectastain ABC kit (Hsu et al., 1981) and visualized with $\mathrm{DAB}$ as a chromogen. Surface preparations were examined by light microscopy. Tissues were then dehydrated and embedded in Epon resin. Radial sections of $6 \mu \mathrm{m}$ were cut on an ultramicrotome (LKB-2088 ultratome V) and heat dried on a glass slide. Photographs were taken on Kodak T-max 100 film.

\section{Fluorescence immunohistochemistry}

Double labeling experiments, in which anti-GST serum was visualized with FITC and anti-tubulin antibody with TRITC as chromophores, were performed on surface preparations obtained as described above for the peroxidase method. Preparations were incubated with the anti-GST antibody (1:100 dilution) for $24 \mathrm{~h}$ at $4^{\circ} \mathrm{C}$. Following three rinses in PBS for $1 \mathrm{~h}$ at RT, preparations were incubated with the FITC-labeled goat anti-rabbit $\operatorname{IgG}(1: 75)$ for $30 \mathrm{~min}$. Tissues were then rinsed in PBS and incubated with the anti-tubulin antibody $(1: 100)$ for $1 \mathrm{~h}$ at RT. Following several rinses in PBS, tissues were incubated with the TRITClabeled anti-mouse $\operatorname{IgG}(1: 75)$ for $30 \mathrm{~min}$. After a final rinse in PBS, the epithelium of the organ of Corti was separated from the bony modiolus and mounted in a solution of $60 \%$ glycerol in sodium carbonate buffer ( $\mathrm{pH}$ 8.5) with p-phenylenediamine as an anti-bleach agent. Tissues were examined and photographed with a Leitz Orthoplan microscope cquipped with epifluorescent illumination using $50 \times$ and $100 \times$ oil immersion

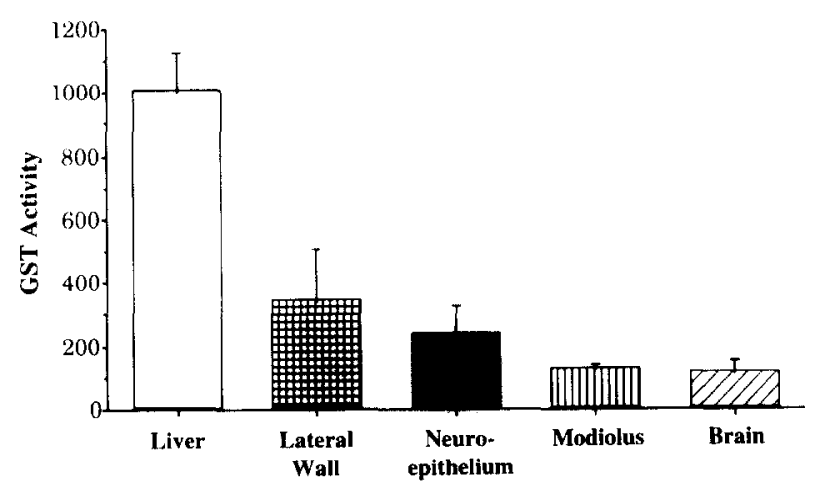

Fig. 1. GST specific activity ( $\mathrm{nmol} / \mathrm{min} \times \mathrm{mg}$ protein) in liver (L), lateral wall (S), neurosensory epithelium (NE), modiolus $(\mathrm{M})$ and brain (B). Enzyme activity was measured as described in 'Methods'. Each bar represents the mean and standard deviation of at least 5 experiments with each experiment run in duplicate.

objectives. Photographs were taken on Kodak T-max 400 film exposed at 1600 ASA.

Some preparations were observed with a MRC BioRAD 600 laser scanning confocal unit attached to a Nikon Diaphot TMD inverted microscope with a $60 \times$ oil immersion objective, N.A. 1.40. The krypton-argon light source was usually attenuated with a 1.0 neutral density filter. Filter cubes for fluorescein contained an exciter filter at $488 \mathrm{~nm}$, dichroic reflector $510 \mathrm{LP}$ (low pass) with a barrier or emission filter at $515 \mathrm{~nm} \mathrm{LP}$. The rhodamine cube contained a band pass filter at $514 \mathrm{~nm}$, a dichroic reflector at $540 \mathrm{~nm}$ LP and emission filter at $550 \mathrm{~nm}$ LP. Fluorescent images were photographed from the video screen.

\section{Results}

\section{GST activity}

Preliminary experiments were performed to determine conditions required for a linear reaction rate over $5 \mathrm{~min}$. The cochlear protein concentrations needed were in the range of $7-10 \mu \mathrm{g}$ protein/ml yielding an absorbance change of $>0.05 / \mathrm{min}$.

The total GST specific activity was highest in liver $(1011 \pm 117 \mathrm{nmol} / \mathrm{min} / \mathrm{mg}$ protein) and low in whole brain $(130 \pm 16)$ (Fig. 1). These values are consistent with those reported by others (Ketterer et al., 1988; Abramovitz et al., 1988). In the inner ear, lateral wall tissues showed highest activity $(348 \pm 158)$, neuroepithelium was intermediate $(240 \pm 86)$ while modiolar preparations were low in GSTs $(117 \pm 36)$. For an assessment of possible sex differences, two preliminary experiments were performed on female Wistar rats. The average values were slightly lower than those of the male in liver (female, 5\% lower), brain (25\%), lateral wall $(25 \%)$, and combined modiolus/neuroepithelium (20\%). 
A

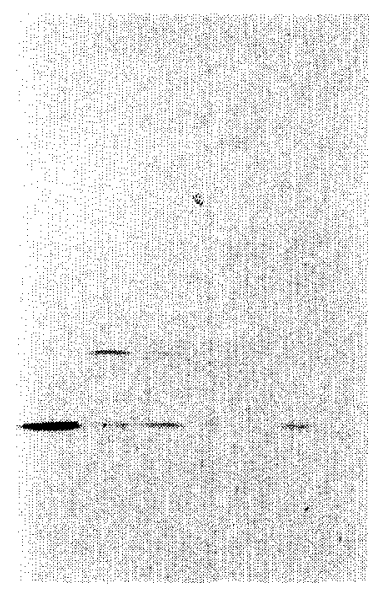

L B C S Std C
B

KD

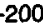

$-97.4$

$-69$

$-46$

$-30$

$-14.3$

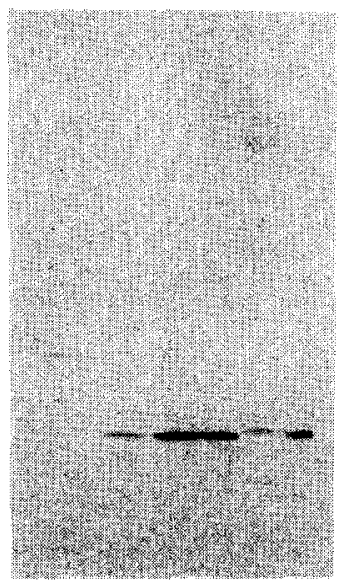

L B C $\mathbf{S}$ Std C
C

$\mathbf{k D}$

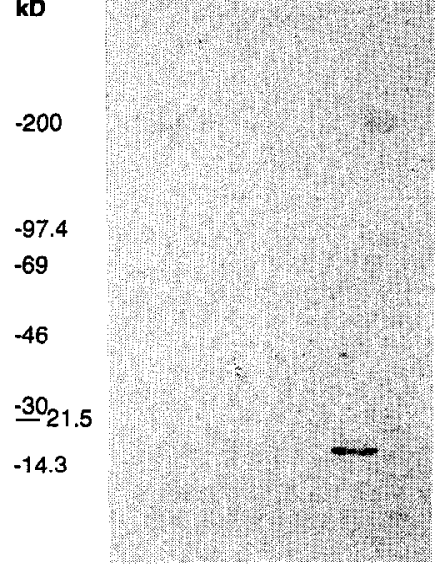

Std S C B L Std

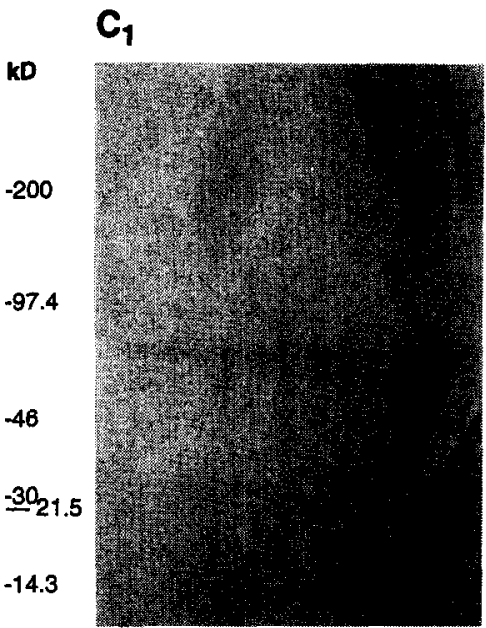

C C Std C S B L Std

Fig. 2. Western blot analysis of liver (L), brain (B), Corti-modiolus (C), lateral wall (S). 'Std' denotes molecular weight standards. Assays were performed as described in 'Methods'. (A) Anti-GST $Y_{b 1}$. Liver shows an intense band between 21.5 and $30 \mathrm{kD}$. Other samples demonstrate a weaker band within the same molecular weight range. (B) Anti-GST $Y_{p}$. This subunit is almost non-existent in the liver. A weak band is apparent for the brain. In contrast, both cochlear samples show intense bands between 21.5 and $30 \mathrm{kD}$. (C) Anti-GST $\mathrm{Y}_{\mathrm{a}}$. The liver shows a dark band and

the other samples appeared to be negative. However, $100 \%$ UV enhancement (C1) resulted in the detection of doublets for all samples.

$\mathrm{K}_{\mathrm{m}}$ for a combined modiolus/neuroepithelium preparation was estimated in two experiments varying the final concentration of GSH from $0.1 \mathrm{mM}$ to $2 \mathrm{mM}$ at a constant concentration of $1 \mathrm{mM}$ CDNB. Lineweaver-Burke analysis gave a linear plot indicating a $\mathrm{K}_{\mathrm{m}}$ of about $0.4 \mathrm{mM}$.

\section{Western blotting}

$\mathrm{Y}_{\mathrm{b} 1}$ antibody (Fig. 2, panel A) reacted intensely with liver extract (L) at a molecular weight corresponding to that reported for $Y_{b 1}$ rat hepatic transferase, $27 \mathrm{kD}$. Brain (B), corti-modiolus (C) and lateral wall tissues (S) samples each showed two bands, one band at the same level as that of liver and a second band close to $50 \mathrm{kD}$. This band could indicate a dimeric form of GST. Cross reactivity with other subunit members of the $\mu$ class have been also reported for this antibody (Hayes and Mantle, 1986), however, the molecular weights of these subunits are close to $26 \mathrm{kD}$.

The $Y_{p}$ subunit (Fig. 2, panel B) was almost non-existent in the liver sample. In contrast, the Corti-modiolus and lateral wall preparations demonstrated an intensely labeled band between 21.5 and $30 \mathrm{kD}$, indicating that the $Y_{p}$ subunit is the predominant form in the cochlear tissues. The molecular weight for $\mathrm{Y}_{\mathrm{p}}$ has been reported to be $24.5 \mathrm{kD}$. The brain displayed a light band at the same level.

Anti-GST $Y_{\mathrm{a}}$ (Fig. 2, panel C) identified a protein in liver between 21.5 and $30 \mathrm{kD}$, whereas no staining was apparent in the other samples. The reported molecular weight of $\mathrm{Y}_{\mathrm{a}}$ is $25.5 \mathrm{kD}$. However, by using $100 \%$ ultraviolet enhancement photography a doublet pattern was detected for all samples. The second band might represent cross-reactivity of this antibody with other members of the a class such as $Y_{c}$ (molecular weight $27.5 \mathrm{kD}$ ).

From these results, $Y_{b 1}$ and $Y_{p}$ were selected for immunocytochemical localization in the neuroepithelium.

\section{Immunocytochemical controls}

The immunofluorescence controls with NRS produced a weak diffuse background staining (Fig. 3A). This fluorescence was considered non-specific as it clearly contrasted with the localized patterns of $\mathrm{Y}_{\mathrm{b} 1^{-}}$ labeling observed in hair cells (Fig. 3B). Control peroxidase experiments were also carried out, where the primary antibody was replaced by NRS at similar dilu-

Fig. 3. Fluoresceine-labeled surface preparations. Experiments were carried out as described in 'Methods'. Figures $3 \mathrm{C}$ and $3 \mathrm{D}$ are in the same plane of focus. Scale bar $=10 \mathrm{~mm}$. (A) Control. The primary antibody was replaced by normal rabbit serum. There is a lack of specific immunoreactivity in the three rows of $\mathrm{OHCs}(1,2,3)$. (B) $\mathrm{Y}_{\mathrm{bl}}$-like immunoreactivity within the three rows of $\mathrm{OHCs}(1,2,3)$. Fluorescence is seen at the apical regions towards the strial side (arrow). (C) Double labeling for $Y_{b 1}$ and tubulin. $Y_{b 1}$-like immunoreactivity (arrow) is seen within the three rows of OHCs. The asterisk denotes the $Y_{b 1}$ labeling within the IHCs above the level of the nucleus. (D) Double labeling for $Y_{b 1}$ and tubulin. Tubulin immunoreactivity shows intense labeling of the pillar cells (Pc), Deiters cells processes (Dc), basal bodies of OHCs (arrow) and microtubules of IHCs (MT). 


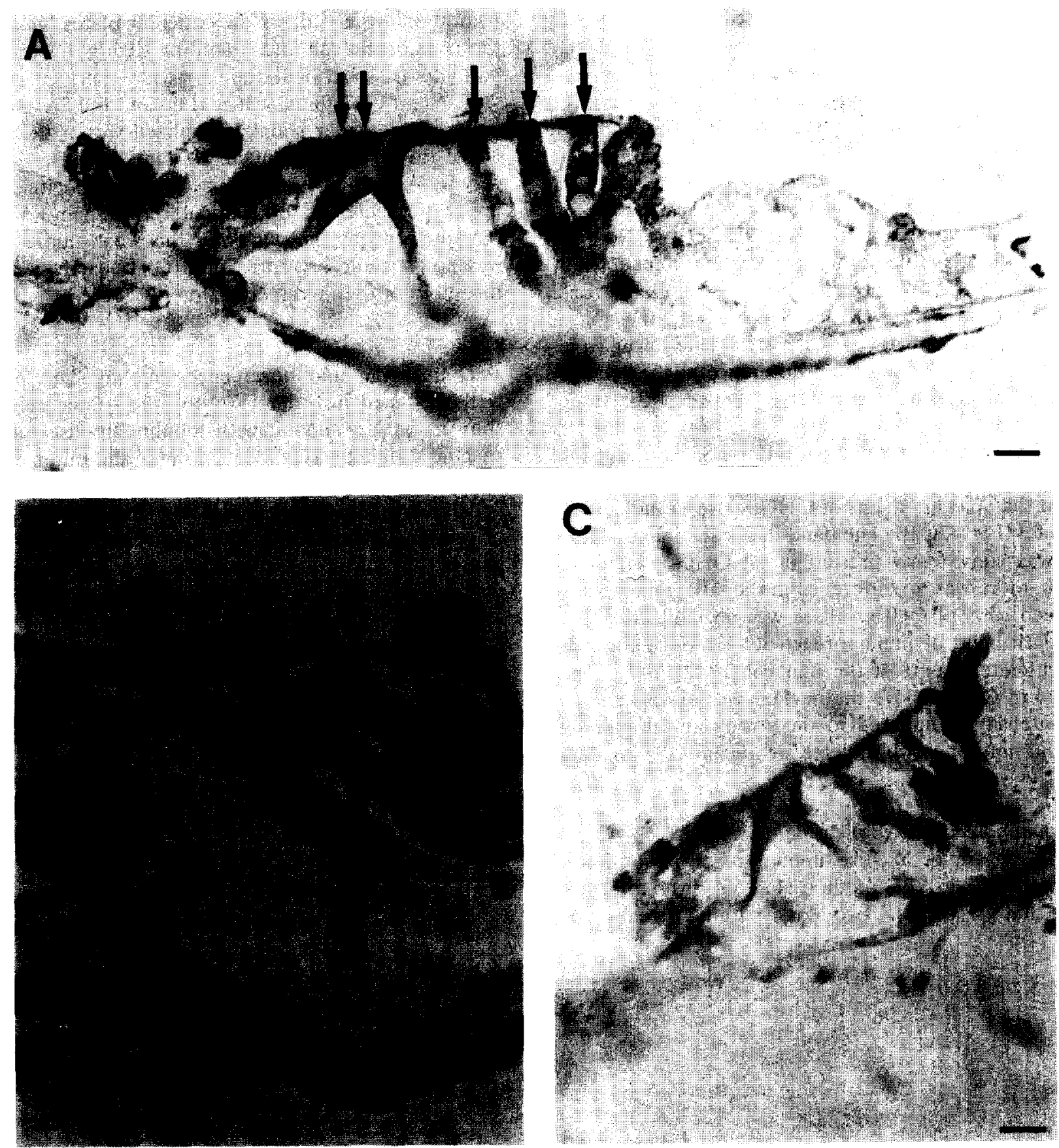

Fig. 4. Radial sections $(6 \mu \mathrm{m})$ of the resin-embedded surface preparations stained with $A B C$ method. Scale bar $=10 \mu \mathrm{m}$. (A) $Y_{b 1}-1$ like immunoreactivity within the apical regions of OHCs (single arrows) close to the cuticular plate. The double arrows point to the $Y_{b 1}$ labeling within the apical domain of IHC as two parallel streaks. (B) High magnification of a radial section showing the pattern of staining in OHCs (3 arrows) and the $\mathrm{Y}_{\mathrm{b} 1}$-like staining within the basilar membrane (thick arrow). (C) Radial section incubated with normal rabbit serum instead of the primary antibody, showing non-specific staining.

tion and protein concentration. These showed nonspecific immunoreactivity in the pillars, the cytosol and nuclei of both inner (IHCs) and outer (OHCs) hair cells (Fig. 4C). However, reactivity at the apical region of OHCs and IHCs (Fig. 4A, B) was not detected in such controls. Replacing the primary antibody with PBS resulted in sections devoid of any staining. Pre-ad- sorption controls had previously been performed on brain sections and had demonstrated the specificity of the antibody (results not shown). Positive controls were conducted with brain sections: immunoreactivity was identified in areas known to be immunopositive for these subunits, specifically the Bergman glial cells of the cerebellum $\left(\mathrm{Y}_{\mathrm{b} 1}\right)$ and oligodendroglia $\left(\mathrm{Y}_{\mathrm{p}}\right)$. 
Outside of the cochlear neuroepithelium, Yb1-like immunoreactivity was seen close to the basilar membrane, presumably associated with fibrocytes and endothelial cells (Fig. 4B). Strong Yp-like immunoreactivity was associated with fibrocytes of the spiral ligament (results not shown).

\section{$Y_{b I}$ immunoreactivity in outer hair cells}

In surface preparations, a characteristic fluorescence pattern in the form of discrete rounded spots (about $2-3 \mu \mathrm{m}$ in diameter) was present in OHCs (Fig. $3 \mathrm{~B}, \mathrm{C})$. These spots were localized only to the apical regions of hair cells towards the strial side (away from the modiolus). No consistent difference in the relative intensity of labeling was observed between the three rows of OHCs.

Radial sections, stained with anti-GST serum using the $\mathrm{ABC}$ method, demonstrated an intense dark band within the apical domains of OHCs close to the cuticular plate (Fig. 4A, B). The band had a semilunar shape and was consistently present in all $\mathrm{OHCs}$ examined. Again, there was no difference in the labeling intensity between rows of OHCs. There was no indication that this dark band of immunoreactivity extended towards the basolateral part of the hair cells. Labeling in the cytosol of OHCs above the nucleus was diffuse and of low intensity. Compared to the strong apical staining this did not appear to indicate significant GST reactivity.

\section{$Y_{b 1}$ immunoreactivity in inner hair cells}

The pattern of $\mathrm{Y}_{\mathrm{b}}$-like immunoreactivity of IHCs obtained by the ABC method (Fig. 4A) was different from that of OHCs. Two dark parallel streaks ap- peared on either side of the cuticular plates, mainly at the apex of the cell and extending slightly towards the basolateral aspect of IHCs.

The anti-GST fluorescence (Figs. 3C and 5A) showed a specific reticular staining localized within the IHCs above the level of the nucleus (asterisk in Fig. 3C). A very weak immunoreactivity incompletely encircled the upper perimeter of the cuticular plate (Fig. 5A). It remained inconclusive whether this wcak fluorescence was non-specific or represented GST-reactivity at the threshold of the immunereaction.

\section{Colocalization}

Double immunofluorescence labeling experiments were designed in order to probe the spatial relationship of the $Y_{b 1}$ subunit with tubulin. Intense tubulinspecific staining was evident in inner and outer pillars, Deiters cells processes, areas of OHCs basal bodies and IHCs microtubules (Fig. 3D). This overall pattern of tubulin labeling is in agreement with that seen in guinea pig surface preparations at a corresponding plane of focus (Steyger et al., 1989; Furness et al., 1990).

For the apical regions of IHCs, Furness et al. (1990) described three major zones of microtubules. The corresponding tubulin-immunofluorescence consisted of an upper ring, a main channel and a lower network. A similar tubulin immunoreactivity can be recognized in the IHCs apices of rat cochlea (Figs. 3D and 5B). The $\mathrm{Y}_{\mathrm{b} 1}$ subunit of GST appeared to follow the same pattern (Figs. 3C and 5A).

For the OHCs, an organization of microtubules qualitatively similar to that of the apical IHCs has been described in the guinea pig (Furness et al., 1990).
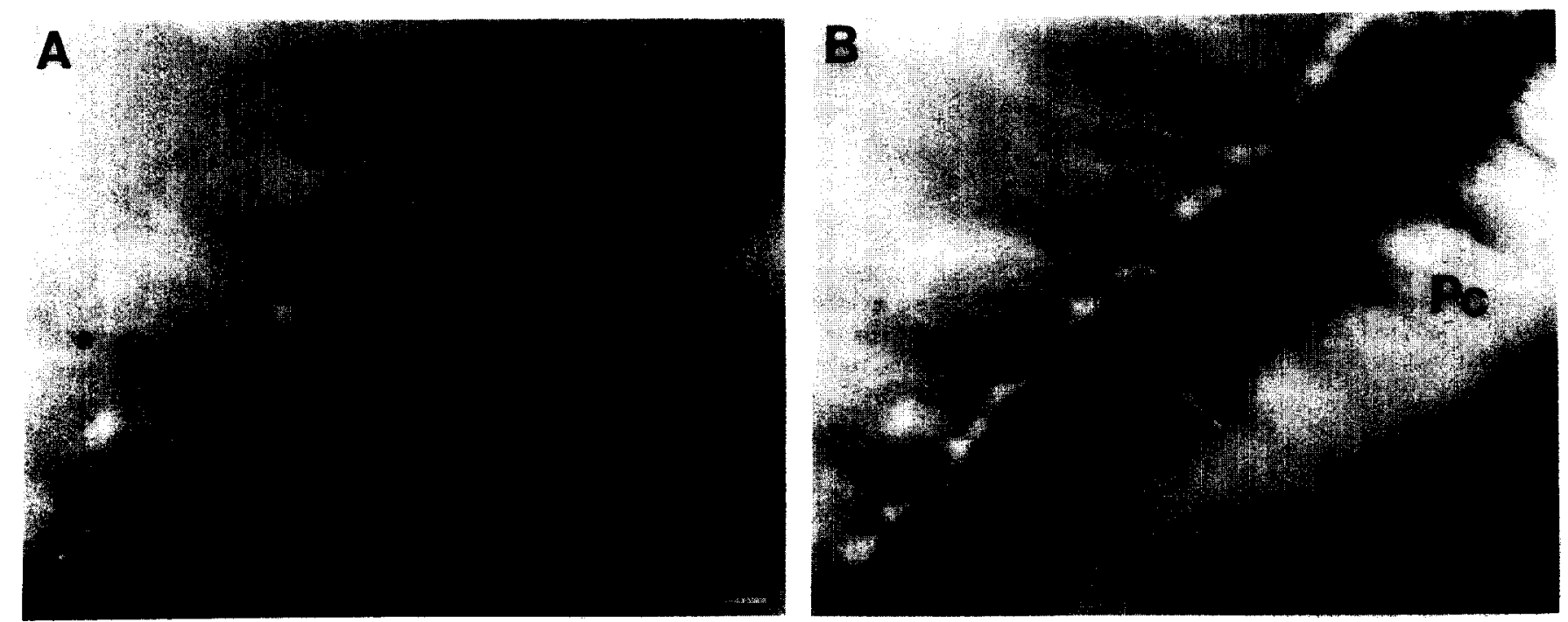

Fig. 5. Double labeling experiment for $\mathrm{Ybl}$ and tubulin. Figs. $5 \mathrm{~A}$ and $\mathrm{B}$ are in the same plane of focus. Scale bar $=10 \mu \mathrm{m}$. (A) Yb1-like immunoreactivity within the IHCs at the level of the cuticular plate. The black and white arrows show the immunoreactivity away from, and towards the stria vascularis respectively. (B) Tubulin immunoreactivity at the level of the cuticular plate of IHCs. The black and white arrows indicate the perimeter with the white arrow pointing towards the pillar cells $(\mathrm{Pc})$ and the stria vascularis. 
Specific to the OHCs, especially those of the apical cochlear turns, was a cuticular plate projection into the cell body with adjacent microtubules. The corresponding tubulin-immunofluorescence showed an area of intense labeling on the strial side at the level of the cuticular plate. An upper fluorescent ring as seen in the IHCs was difficult to detect in OHCs (Steyger et al., 1989). We could also not recognize a ring of tubulin-fluorescence at the level of the cuticular plate. However, a dense tubulin fluorescence patch on the strial side of OHCs was evident (Fig. 3D). This patch seemed to decrease in intensity as the plane of focus was moved down the cell body. The $Y_{t 1}$-like immunoreactivity within the three rows of $\mathrm{OHC}$ appeared to correspond to the tubulin-labeling (Fig. 3C, D). In contrast, no $\mathrm{Y}_{\mathrm{b} 1}$-specific staining was evident in the tubulin-positive supporting cells (Figs. $3 \mathrm{C}$ and $\mathrm{D}$ are in the same plane of focus).

\section{$Y_{p}$ immunoreactivity}

Yp-like immunoreactivity appeared specifically localizcd to Deitcrs ccll processes and pillar cells with sparing of the OHCs (Fig. 6). There was no qualitative difference in labeling between the three rows of Deiters cells. The Yp-immunoreactivity within the supporting cells also colocalized with b-tubulin in these regions (tubulin-immunoreactivity in Fig. 3D). In IHCs, label- ing was identified as a circular ring at the level of the cuticular plate.

\section{Discussion}

The major findings of this study are: (1) GST specific activities in rat cochlear tissues are higher than in brain, (2) of the cytosolic GST isoforms, $Y_{p}(\pi$ class) is quantitatively the predominant isozyme while $\mathrm{Y}_{\mathrm{a}}(\alpha$ class) is virtually absent; and (3) there is a differential cellular distribution of the $Y_{b 1}$ ( $\mu$ class) and $Y_{p}$ subunits. $Y_{b 1}$-like immunoreactivity close to the cuticular plates of OHCs and IHCs appeared to correspond to the region where the basal bodies and microtubules reside, respectively (Engstrom et al., 1966; Steyger et al., 1989; Furness et al., 1990). $Y_{p}$ seems to be specific for Deiters and pillar cells where it also colocalizes with tubulin.

High GST activities are in general considered to represent an elevated detoxifying potential of a tissue as excmplificd by liver. The clevated activity in the lateral wall tissues may thus indicate a local detoxifying site in the inner ear. The low specific activities of GSTs in the neuroepithelium and modiolus are consistent with those in neural tissues such as brain. However, GSTs and glutathione participate in a number of path-
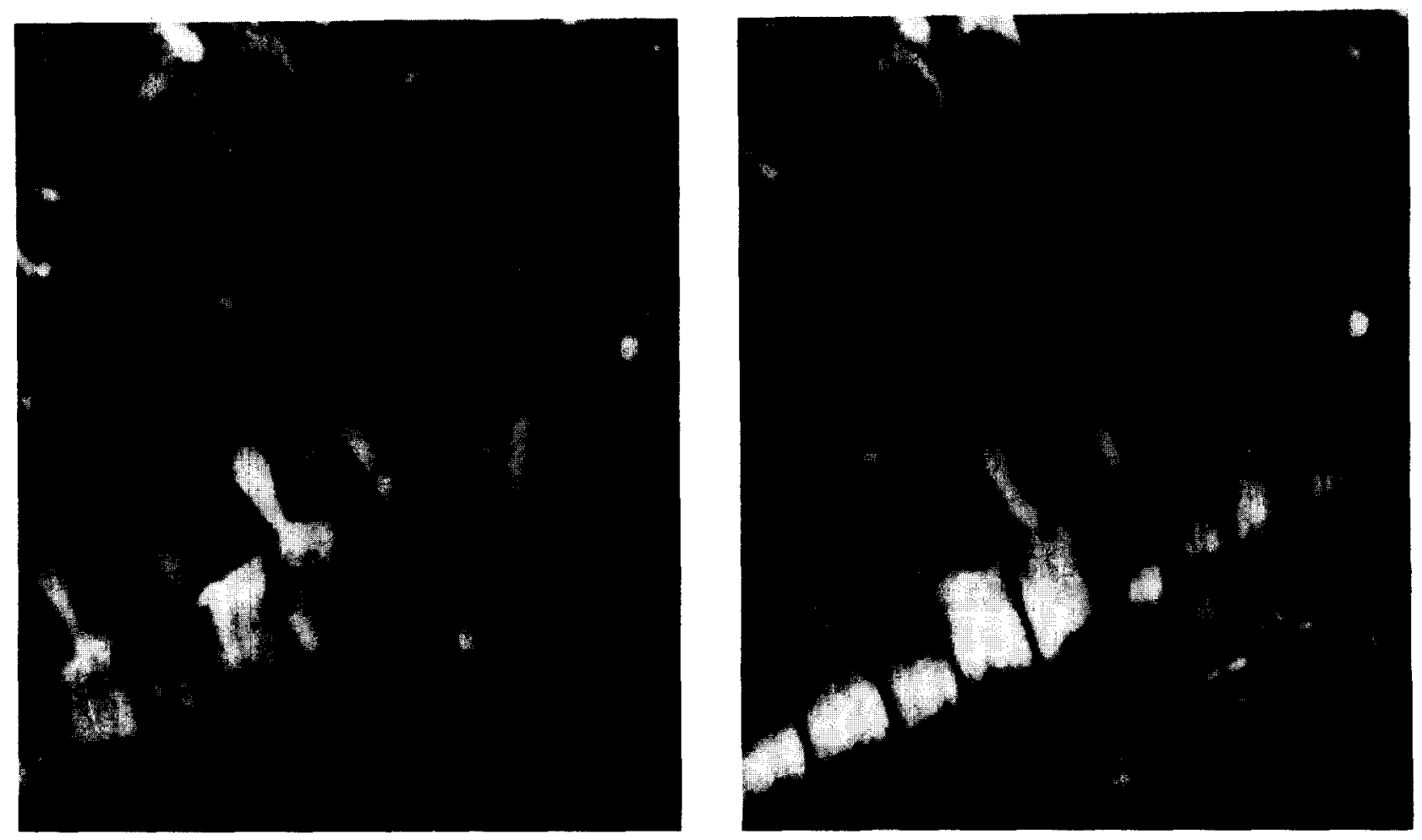

Fig. 6. Confocal scanning microscopic image of a surface preparation of the neurosensory epithelium immunostained with anti-GST Yp. Scale bar $=32 \mu \mathrm{m}$. (A) Yp-like immunoreactivity localized to Deiters cell processes (Dc) and pillar cells (Pc). The three rows of OHCs are marked as 1, 2, 3. (B) Same specimen as in A but focal plane $1 \mu \mathrm{m}$ deeper. In addition to the signal in supporting cells, immunoreactivity is evident at the upper level of the cuticular plate of IHCs. 
ways besides those linked to detoxifying processes. The $\mu$ class GST in brain has been implicated in the selective function of the blood-brain barrier based on its localization to the astrocytic foot processes. The $\pi$ class, associated with myelin-forming cells, has been thought of as protecting the myelin structure (Tansey and Cammer, 1991). GS''s and glutathione are also involved in prostaglandin synthesis (Burgess et al., 1987; Chang et al., 1990). In the inner ear, prostaglandin synthesis has been shown for lateral wall tissues in the guinea pig (Escoubet et al., 1985) and for the organ of Corti in the gerbil (Kawata et al., 1988). It remains to be established whether and where in the inner ear GSTs have analogous roles in the biochemical pathways mentioned.

The cochlear GST subunits, recognized by antibodies to hepatic GST subunits, displayed a molecular weight range of $21.5-30 \mathrm{kD}$, consistent with the reported molecular weights of $Y_{p}(24.5 \mathrm{kD}), Y_{a}(25.5 \mathrm{kD})$ and $Y_{b 1}(27 \mathrm{kD})$ (Bass et al., 1977; Hayes et al., 1986). The pattern of subunit distribution in the inner ear was distinct from that in liver and brain. $Y_{p}$ which is absent from liver was the predominant cochlear isoform, $Y_{b 1}$ was present to a lesser extent and $Y_{a}$ was barely detectable in the cytosolic fraction. Since GST isozymes have different although somewhat overlapping substrate specificities (Ketterer et al., 1988), differential distribution patterns result in metabolic differences and confer different protective potentials. The isozyme profile of the cochlear tissues may therefore be an important parameter in evaluating GSH-mediated protection from auditory pathology.

The apical portion of hair cells where $Y_{b 1}$ was localized may be a strategic place for a detoxifying enzyme. Toxins delivered through the microcirculation to the scala media would reach the hair cells via their apical membranes where the actin-free zone may be an entry gate. Conversely, endogenous toxins could be cleared here after interactions with the enzyme as a detoxifying agent. In this respect, it is interesting that the early morphological changes in reponse to aminoglycoside treatment include the accumulation of lysosomes and Golgi membranes beneath the cuticular plate (deGroot et al., 1990). Recently, labeled gentamicin was localized in apical regions of OHCs and IHCs of guinea pigs shortly after treatment and prior to impairment of cochlear functions (Hiel et al., 1992). GSTs detoxify xenobiotics by catalyzing the formation of glutathione conjugates (Jakoby, 1978; Mannervik, 1985). While little is known about the role of glutathione in the inner ear, systemic inhibition of glutathione synthesis has been shown to potentiate the ototoxicity of combined ethacrynic acid and kanamycin (Hoffman et al., 1988). Conversely, glutathione appeared to protect isolated OHCs from a cytotoxic gentamicin metabolite (Garetz and Schacht, 1992) and guinea pigs in vivo from gentamicin-induced ototoxicity (Garetz et al., 1993).

The cell-specific distribution of GST isozymes in the cochlea may contribute to the differential susceptibility of sensory and supporting cells to certain ototoxic drugs. $Y_{p}$ has been linked to dysplastic and malignant transformations in cells of different organs (Obara et al., 1986; Pemble et al., 1986; Shiratori et al., 1987) and increased expression of $Y_{p}$ in neoplastic cells has been associated with multi-drug resistance to chemotherapeutic agents.

The localization of $Y_{p}$ to Deiters cells is intriguing beyond the possible implications for drug susceptibility. From studies of tumor cells it has been proposed that selective overexpression of certain GST isozymes confers a replicative advantage to dedifferentiated cells (Hayes et al., 1991). This hypothesis is interesting in view of the fact that Deiters cells have recently been shown to participate in scar formation after hair cell loss (Raphael and Altschuler, 1991).

Finally, a link of GSTs with the microtubule system in inner car cells is a possibility. This can be hypothesized based on the immunohistochemical colocalization of $Y_{b 1}$ with tubulin in the sensory cells and of $Y_{p}$ with tubulin in Deiters and pillar cells. An association of glutathione with the microtubule system has been infered from studies of cell cultures. Treatment of Swiss 3T3 cells with 1-chloro-2,4-dinitrobenzene, a potent substrate for GST, led to cellular depletion of glutathione and disassembly of microtubules. The resulting shape changes were similar to those induced by colchicine, a microtubule-depolymerizing drug (Chou and Shaw, 1984). Another neuroloxic drug, methyl mercury, appeared to selectively precipitate microtubules in cultured mouse neuroblastoma cells. Glutathione afforded protection against this cytoskeletal neurotoxicity (Trombetta and Kromidas, 1992). Furthermore, the ototoxic diuretic, ethacrynic acid, is a GST substrate and has been reported to induce reversible shape and cytoskeletal changes in cultured cells which are preceeded by disruption of microtubules (Erickson-Lamy et al., 1992). In vitro, ethacrynic acid inhibits microtubule assembly (Xu et al., 1992).

Microtubules participate in the organization of cytoplasmic organelles (Thyberg and Moskalewski, 1985; Kreis, 1990), cell motility, the development and maintenance of cell asymmetry, cell division and morphogenesis (Dustin, 1978). The basal bodies in ciliated cells and unicellular flagellated algae are the functional homologues of the centrosome in higher animal cells, the site for the assembly of the flagella and also of cytoplasmic microtubules. During their development, mammalian hair cells display kinocilia which are lost with maturation (Kikuchi and Hilding, 1965; Kimura, 1966) whereas the basal bodies are retained. The function, structure and biochemical composition of these 
basal bodies are not completely understood. It is possible that $Y_{b 1}$ is one of the protein components of the microtubule organizing center of hair cells. Likewise, $Y_{p}$ could be one of the proteins involved in the regulation of microtubule polymerization within Deiters cells. The differential cellular distribution of the $Y_{b 1}$ and $Y_{p}$ subunits would then reflect a functional cytoskeletal differences in sensory versus supporting cells.

The present results provide the basis for further investigations that eventually should establish the function of these enzymes in cochlear physiology and pathophysiology.

\section{Acknowledgements}

The authors thank Drs. Donald Coling and Yehoash Raphael for their valuable suggestions and criticism and Walter Meixner (DMSV Laboratory) for assistance with confocal microscopy. This work was supported by research grant DC-00124 from The National Institutes of Health.

\section{References}

Abramovitz, M., Homma, H., Ishigaki, S., Tansey, F., Cammer, W. and Listowsky, I. (1988) Characterization and localization of glutathione S-transferases in rat brain and binding of hormones, neurotransmitters and drugs. J. Neurochem. 50, 50-57.

Bass, N.M., Kirsch, R.E., Tuff, S.A. and Saunders, S.J. (1977) Radioimmunoassay of ligandin. Biochim. Biophys. Acta 494, 131134.

Boyer, T.D. (1989) The glutathione S-transferases: an update. Hepatology 9, 486-496.

Burgess, J.R., Yang, H., Chang, M., Rao, M.K., Tu, C.-P.D. and Reddy, C.C. (1987) Enzymatic transformation of PGH2 to PGF2a catalyzed by glutathione S-transferases. Biochem. Biophys. Res. Commun. 142, 441-447.

Cammer, W., Tansey, F., Abramovitz, M., Ishigaki, S. and Listowsky, I (1989) Differential localization of glutathione S-transferases Yp and $\mathrm{Yb}$ subunits in oligodendrocytes and astrocytes of rat brain. J. Neurochem. 52, 876-883.

Carillo, M.-C., Nokubo, M., Kitani, K., Satoh, K. and Sato, K. (1991) Age-related alterations of enzyme activities and subunits of hepatic glutathione S-transferases in male and female Fischer-344 rats. Biochim. Biophys. Acta 1077, 325-331.

Chang, M., Burgess, J.R., Scholz, R.W. and Reddy, C.C. (1990) The induction of spccific rat liver glutathione $S$-transferase subunits under inadequate selenium nutrition causes an increase in prostaglandin F2a formation. J. Biol. Chem. 265, 5418-5423.

Chou, I.N. and Shaw, J.P. (1984) Microtubule disassembly and morphologic alterations induced by 1-chloro-2,4-dinitrobenzene, a substrate for glutathione S-transferase. Cell Biol. Inter. Rep. 8, 441-448.

DeGroot, J.C.M.J., Meeuwsen, F., Ruizendaal, W.E. and Veldman, J.E. (1990) Ultrastructural localization of gentamicin in the cochlea. Hear. Res. 50, 35-42.

Dustin, P. (1984) General physiology of tubulins and microtubules. In: A.P. Dustin (Ed), Microtubules, Springer-Verlag, New York, pp. 98-118.
Engstrom, H., Ades, H.W. and Anderson, H. (1966) Structural pattern of the organ of Corti. A systematic mapping of sensory cells and neural elements. Almqvist and Wiksell, Stockholm, pp. $39-61$.

Erickson-Lamy, K., Schroeder, A. and Epstein, D. (1992) Ethacrynic acid induces reversible shape and cytoskeletal changes in cultured cells. Invest. Ophthalmol. Vis. Sci. 33, 2631-2640.

Escoubet, B., Amsallem, P., Ferrary, E., Tran Ba Iluy, P. (1985) Prostaglandin synthesis by the cochlea of the guinea pig. Prostaglandin 29, 589-599.

Furness, D.N., Hackney, C.M. and Steyger, P.S. (1990) Organization of microtubules in cochlear hair cells. J. Electron Micros. Tech. $15,261-279$.

Garetz, S.L. and Schacht, J. (1992) Sulfhydryl compounds reduces gentamicin-induced outer hair cell damage in vitro. Abstr. Assoc. Res. Otolaryngol.

Garetz, S.L., Rhee, D.J. and Schacht, J. (1993) Attenuation of gentamicin ototoxicity by glutathione. Abstr. Assoc. Res. Otolaryngol.

Habig, W.H., Pabst, M.J. and Jakoby, W.B. (1974) Glutathione $\mathrm{S}$-transferascs. The first enzymatic step in mercapturic acid formation. J. Biol. Chem. 249, 7130-7139.

Hayes, J.D. and Mantle, T.J. (1986) Use of immunoblot techniques to discriminate between the glutathione S-transferase Yf, Yk, $\mathrm{Yn} / \mathrm{Yb}$ and $\mathrm{Yc}$ subunits and to study their extra-hepatic distribution. Binchem. I. 233, 779-788.

Hayes, P.C., Bouchier, I.A.D. and Beckett, G.J. (1991) Glutathione S-transferase in humans in health and disease. Gut 32, 813-818.

Hiel, H., Bennani, H., Erre, J.P., Aurousseau, C. and Aran, J.M. (1992) Kinetics of Gentamicin in cochlear hair cells after chronic treatment. Acta Otolaryngol (Stockh) 112, 272-277.

Hoffman, D.W., Jones-King, K.L., Whitworth, C.A. and Rybak, L.P. (1988) Potentiation of ototoxicity by glutathione depletion. Ann. Otol. Rhinol. Laryngol. 97, 36.

Hsu, S.-M., Raine, L. and Fanger, H. (1981) Use of avidin-biotin-peroxidase complex $(\mathrm{ABC})$ in immunoperoxidase techniques. J. Histochem. Cytochem. 29, 577-580.

Jakoby, W.B. (1978) The glutathione S-transferases: a group of multi-functional detoxification proteins. Adv. Enzymol. 46, 383414.

Johnson, J.A., El Barbary, A., Kornguth, S.E., Brugge, J.F. and Siegel, F.L. (1993) Glutathione S-transferases Isoenzymes in rat brain neurons and glia. J. Neurosc.13, 2013-2023.

Kawata, R., Urade, Y., Tachibana, M. and Mizukoshi, O. (1988) Prostaglandin synthesis by the cochlea. Prostaglandin 35, 173-184.

Ketterer, B., Meyer, D.J. and Clark, A.G. (1988) Soluble glutathione transferaseisozymes. In: H. Sies and B. Ketterer (Eds), Glutathione conjugation: mechanism and biological significances, Academic Press, London, pp. 73-135.

Kikuchi, K. and Hilding, D. (1965) The development of the organ of Corti in the mouse. Acta Otolaryngol. 60, 207-222

Kimura, R.S. (1966) Hairs of the cochlear sensory cells and their attachment to the tectorial membrane. Acta Otolaryngol. 61, $55-72$.

Kreis, T.E. (1990) Role of microtubules in the organisation of the golgi apparatus. Cell Motil. 15, 67-70.

Listowsky, I., Abramovitz, M., Homma, H. and Niitu, Y. (1988) Intracellular binding and transport of hormones and xenobiotics by glutathione S-transferases. Drug Met. Rev. 19, 305-318.

Mannervik, B. (1985) The isozymes of glutathione transferase. Adv. Enzymol. 57, 357-417.

Mannervik, B., Alin, P., Guthenberg, C., Jensson, H., Tahir, M.K., Warholm, M. and Jornvall, $H$. (1985) Identification of three classes of cytosolic glutathione transferase common to several mammalian species: correlation between structural data and enzymatic properties. Proc. Natl. Acad. Sci. USA 82, 7202-7206.

Mannervik, B. and Danielson, U.H. (1988) Glutathione transferase. 
Structure and catalytic activity. CRC Crit. Rev. Biochem. 23, 283-337.

Maruyama, H. and Listowsky, I. (1984) Preferential binding of steroids by anionic forms of rat glutathione S-transferase. J. Biol. Chem. 259, 12449-12455.

Meister, A. (1991) Glutathione deficiency produced by inhibition of its synthesis, and its reversal; application in research and therapy. Pharmac. Ther. 55, 155-194.

Obara, T., Makino, T., Ura, H., Yokose, Y., Kinugosa, T., Moore, M.A., Sato, K. and Konishi, Y. (1986) Comparative histochemical investigation of the glutathione S-transferases placental form and gamma-glutamyl transpeptidase during $\mathrm{N}$-nitrosobis (2-hydroxy propylamine) induced pancreatic carcinogenesis in hamsters. Carcinogenesis 7, 801-805.

Pemble, S.E., Taylor, J.B. and Ketterer, B. (1986) Tissue distribution of rat glutathione transferases subunit 7 , a hepatoma marker. Biochem. J. 240, 885-889.

Raphael, Y, and Altschuler, R.A. (1991) Reorganization of cytoskeletal and functional proteins during cochlear hair cell degeneration. Cell Motil. Cytoskel. 18, 215-227.

Reed, D.J. and Fariss, M.W. (1984) Glutathione depletion and susceptibility. Pharmacol. Rev. 36, 25S-33S.

Rogiers, V., Coecke, S., Vandenberghe, Y., Morel, F., Callaerts, A., Verleye, G., Van Bezooijen, C.F.A., Guillouzo, A. and Vercruysse, A. (1991) Effect of the aging process on the gender and phenobarbital dependent expression of glutathione S-transferase subunits in Brown Norway rat liver. Biochem. Pharmacol. 42, 491-498.

Senjo, M., Ishibashi, T., Terashima, T. and Inoue, Y.(1986) Successive appearance of glutathione S-transferase positive cells in developing rat brain: choroid plexus, pia mater, ventricular zone and astrocytes. Neurosci. Lett. 66, 131-134.

Shiratori, Y., Soma, Y., Maruyama, H., Sato, S., Takano, $\Lambda$. and Sato, K. (1987) Immunohistochemical detection of the placental form of glutathione S-transferases in dysplastic and neoplastic human uterine cervix lesions. Cancer Res. 117, 6806-6809.

Steyger, P.S., Furness, D.W., Hackney, C.M. and Richardson, G.P. (1989) Tubulin and microtuhules in cochlear hair cells: Comparative immunocytochemistry and ultrastructure. Hear. Res. 42, 1-16.

Tansey, F.A. and Cammer, W. (1991) A pi form of glutathione S-transferase is a myelin and oligodendrocytes-associated enzyme in mouse brain. J. Neurochem. 57, 95-102.

Thyberg, J. and Moskalewski, S. (1985) Microtubules and the organization of the Golgi complex. Exp. Cell Res. 159, 1-16.

Trombetta, L.D. and Kromidas, L. (1992) A scanning electron-microscopic study of the effects of methylmercury on the neuronal cytoskeleton. Toxicol. Lett. 60, 329-341.

Xu, S., Roychowdhury, R., Gaskin, F. and Epstein, D.L. (1992) Ethacrynic acid inhibition of microtubule assembly in vitro. Arch. Biochimm. Biophys. 296, 462-467. 